\title{
Zufallsfund bei Pneumonie-Fahndung
}

Zunächst schien sich der Verdacht auf eine Lungenentzündung bei der 72-jährigen Patientin mit fieberhaftem Infekt zu bestätigen. Auch das Röntgenbild wies in diese Richtung. Das Computertomogramm (CT) offenbarte dann allerdings eine ganz andere Diagnose.

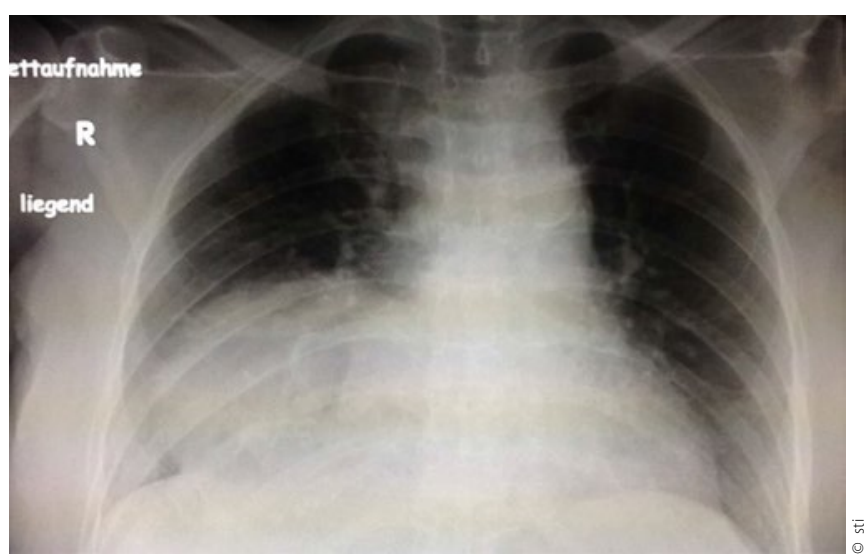

Röntgen-Thorax: Ausgedehnte Verschattung im rechten Lungenunterfeld.

Die Patientin erkrankte akut mit Fieber, Atemnot und Husten. Bei der klinischen Untersuchung wurde über dem rechten Lungenunterfeld ein abgeschwächtes Atemgeräusch auskultiert. Laborchemisch fand sich ein leicht erhöhter CRP-Wert (3 mg/dl), die Leukozytenzahl war nicht erhöht.

Bei Verdacht auf eine Pneumonie wurde eine Röntgen-ThoraxAufnahme angefertigt. Hier fand sich eine ausgedehnte homogene Verschattung im Bereich des rechten Lungenunterfeldes. Der Befund ist nicht ganz typisch für eine Lobärpneumonie. Differenzialdiagnostisch wurde daher auch eine Atelektase und ein Tumor diskutiert. Zur weiteren Abklärung wurde eine CT durchgeführt: Sie zeigt einen intrathorakalen Magen im Sinn einer Bochdaleck-Hernie. Dabei handelt es sich um einen Zufallsbe-

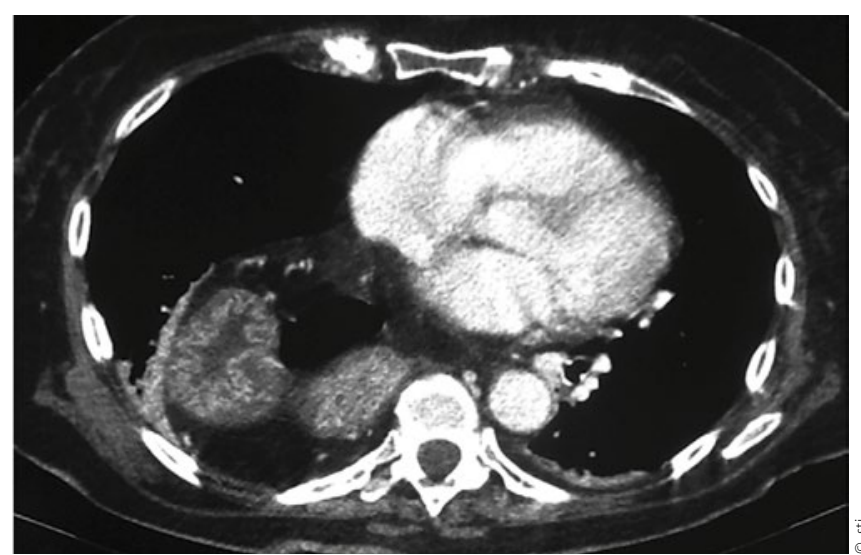

CT-Thorax: Hernierte Magenanteile im Thorax.

fund, der mit dem respiratorischen Infekt in keinem kausalen Zusammenhang steht. Im rechten Zwerchfell gibt es eine Schwachstelle, nämlich das Trigonum lumbocostale, das zu einer Hernisation neigt, an dieser Stelle können sich Eingeweide aus dem Bauchraum in den Thoraxraum vorwölben. Meist ist eine solche Hernie angeboren. Da sie zu einer starken Verdrängung der rechten Lunge und somit zu einer respiratorischen Insuffizienz führen kann, müssen betroffene Kinder meist früh, manchmal sogar notfallmäßig operiert werden. Doch auch während des Lebens kann sich eine solche Hernie ohne erkennbare Ursache entwickeln und wird, wie bei dieser Patientin, meist nur zufällig entdeckt, da sie keine besonderen Beschwerden verursacht. Dann besteht auch kein Handlungsbedarf.

Dr. med. Peter Stiefelhagen

\section{Quiz Hautbefund Teil 1}

\section{Derber Knoten am Kopf}

Ein 58-jähriger Raucher, bei dem keine ernsthaften Vorerkrankungen bekannt sind, bemerkte eine größer werdende Schwellung an der linken Kopfseite temporal. Bei der klinischen Untersuchung imponierte der etwa kirschgroße, flammend rote, nicht schmerzhafte Tumor sehr derb und war nicht auf der Unterlage verschieblich. Das Labor zeigte eine maximal beschleunigte Blutkörperchensenkungsgeschwindigkeit und eine leichte normochrome Anämie. Der Patient gab an, dass er in den letzten Wochen ca. $5 \mathrm{~kg}$ an Gewicht verloren habe. Des Weiteren habe er eine leichte Dyspnoe verspürt, und der Auswurf sei einmal leicht blutig tingiert gewesen.

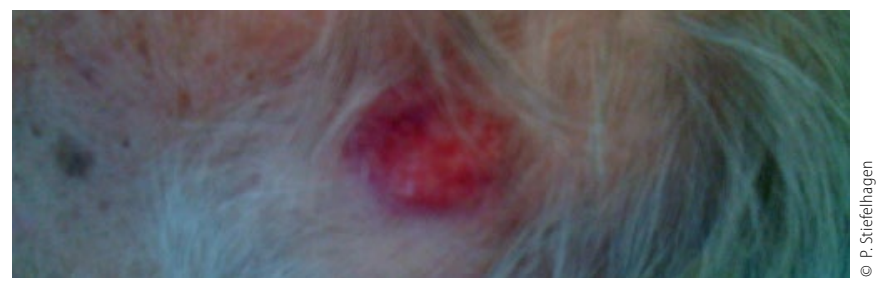

Flammend roter, nicht schmerzhafter Tumor an der linken Kopfseite temporal.

Welche Verdachtsdiagnose stellen Sie? (Lösung S. 25)

A. Infiziertes Atherom

B. Exostose

C. Hautmetastase eines Bronchialkarzinoms

D.Malignes Melanom 